\title{
Atenção Primária à Saúde na Espanha
}

Primary Health Care in Spain

\section{Atención Primaria de Salud en España}

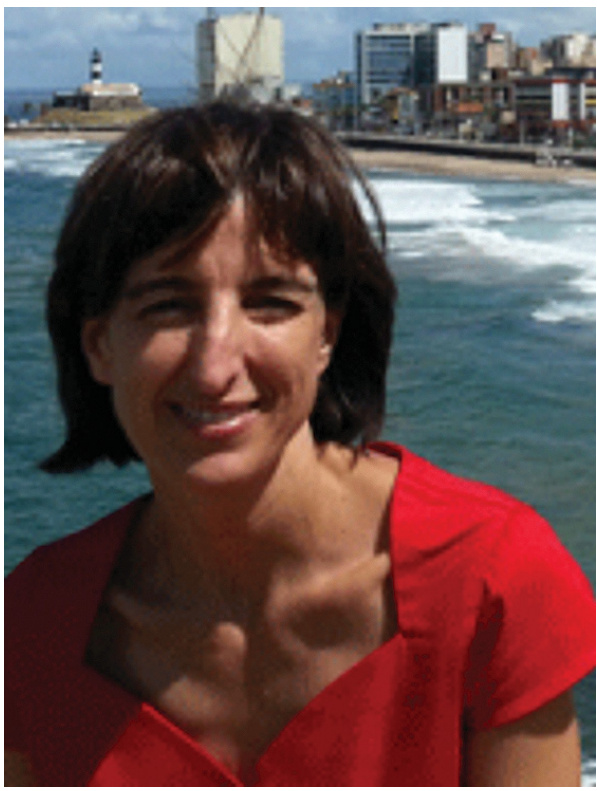

Maria Pilar Astier-Peña é licenciada e doutora em Medicina e Cirurgia pela Universidad de Zaragoza, Espanha. Possui Mestrado em Saúde Pública e Administração Sanitária pela Universidad de Valencia e Mestrado em Economia da Saúde e Gestão Sanitária pelas Universidades Central de Barcelona e Pompeu Fabra. Atualmente Pilar é médica de família e comunidade e coordenadora médica do Centro de Saúde de Caspe (Zaragoza) do Serviço Aragonês de Saúde e realiza, também, pesquisa sobre sistemas de informação e projetos de melhoria da qualidade assistencial no âmbito hospitalar. Em agosto deste ano, esteve no Brasil, ocasião em que visitou Clínicas da Família no Rio de Janeiro e ministrou oficinas para os residentes e preceptores do Programa de Residência em Medicina de Família e Comunidade da Secretaria Municipal de Saúde do Rio de Janeiro. 


\section{RBMFC: Qual é a situação atual da atenção primária na Espanha e qual é o papel do médico de família e comunidade?}

Pilar Astier: O sistema nacional de saúde na Espanha está atualmente organizado em 17 serviços regionais de saúde, que, em seu conjunto, possuem 3.600 centros de saúde e 10.116 consultórios locais em pequenos vilarejos, onde os profissionais de saúde trabalham para dar conta de uma populaçáo de 47.213 .000 habitantes.

Em cada centro de saúde trabalha uma equipe de atenção primária composta por médicos de família e comunidade, pediatras, profissionais de enfermagem, uma enfermeira obstetra e, em algumas equipes, também um odontólogo. Essa equipe conta com o apoio de profissionais administrativos. Cada equipe é responsável por uma população específica chamada de "zona básica de saúde", e cada médico de família e comunidade tem sob sua responsabilidade entre 1500 e 2000 habitantes.

Cada zona básica tem um hospital de referência com serviço de emergência, internação e atenção especializada ambulatorial, para que os médicos de família e comunidade possam encaminhar os pacientes para avaliação especializada.

Os médicos do centro de saúde oferecem consultas médicas em função da demanda do paciente, bem como consultas programadas com o objetivo de fazer um acompanhamento dos processos crônicos. Eles realizam visitas domiciliares para pacientes com dificuldades de se deslocar à unidade de saúde, tanto de forma programada como por solicitação do próprio paciente.

Os médicos têm o apoio de profissionais de enfermagem para as atividades de promoção da saúde, acompanhamento de pacientes crônicos e de pacientes em cuidados domiciliares, bem como para a coleta de sangue, dispensaçáo de medicamentos e realização de curativos.

Cada serviço regional de saúde oferece às suas equipes de atenção primária um prontuário eletrônico comum para toda a regiấo, um sistema de prescrição eletrônica e conexão com o sistema de informação da atenção especializada, que permite ter acesso aos exames radiológicos e aos resultados de exames laboratoriais do hospital de referência, e, em algumas regióes, também aos registros clínicos hospitalares.

A maioria dos profissionais de saúde das equipes de atenção primária é assalariada e pertence ao serviço regional de saúde. Os centros de saúde empregam mais de 35.000 médicos (29.000 médicos de família e comunidade e 6.000 pediatras), dos quais 50\% aproximadamente são mulheres. Quanto aos profissionais de enfermagem, cerca de 29.000 (8 de cada 10) são mulheres. A razão de médicos de família e comunidade por cada 10.000 habitantes é de 7,6 e, de enfermeiros, 6,3.

Nos centros de saúde rurais, os médicos realizam a atenção continuada de 24 horas, para que a população sempre tenha acesso a um médico de família e comunidade de forma programada ou urgente.

RBMFC: Quais são os principais problemas que a atenção primária atravessa neste momento?

Pilar Astier: Em primeiro lugar, o perfil de nossos pacientes. Com o envelhecimento populacional - 17,4\% da populaçáo tem idade superior a 65 anos -, os pacientes passaram a apresentar mais comorbidades e, assim, maior uso de polifarmácia. O médico de família e comunidade, portanto, deve estar capacitado para detectar interaçóes medicamentosas, manejar fármacos com janela terapêutica estreita (p.ex., digoxina, anticoagulantes, antiepilépticos e opioides) e para buscar reduzir o risco de eventos adversos relacionados a medicamentos ( $47 \%$ dos eventos adversos na atençáo primária da Espanha são relacionados a medicamentos).

Por outro lado, com o aumento da prevalência de doenças crônicas, como diabetes, hipertensão, obesidade e artrose, aumentou a carga de cuidados que essa população requer, tornando necessário buscar novas formas de cuidados e empoderar os pacientes para que eles possam conduzir sua própria doença por meio de "programas de pacientes especialistas".

Outra dificuldade é a limitação de acesso aos dados do prontuário eletrônico entre as comunidades autônomas. Os pacientes que se deslocam para outras regiōes não têm à sua disposição um conjunto mínimo de informaçôes sobre sua saúde. $\mathrm{O}$ paciente deve levar ele mesmo seus relatórios médicos. O mesmo ocorre com a prescrição eletrônica, que somente pode ser usada na regiâo do paciente e não é compartilhada com as outras regióes.

Quanto aos profissionais, a situação econômica atual está gerando importantes cortes nos orçamentos da saúde. Na atenção primária, isso afeta diretamente os profissionais, que tiveram a sua carga horária semanal aumentada e os salários diminuídos. Houve também diminuição da contratação de profissionais substitutos para períodos de férias, congressos, etc., e dos investimentos em equipamentos. 
"Dois elementos que me parecem fundamentais são o planejamento do processo e o uso de indicadores para avaliar os resultados sobre a saúde da população, permitindo valorizar adequadamente o trabalho das equipes de atenção primária".

RBMFC: Na sua recente visita ao Brasil, o que mais lhe chamou a atenção no sistema de saúde brasileiro e, principalmente, no processo de transformação da APS que está sendo implementado no Rio de Janeiro?

Pilar Astier: A oportunidade de compartilhar alguns dias com vocês me permitiu conhecer como funcionam as equipes de atenção primária, como se formam os residentes de medicina de família e comunidade e como está sendo planejada a implantação das novas equipes.

Dois elementos que me parecem fundamentais são o planejamento do processo e o uso de indicadores para avaliar os resultados sobre a saúde da população, permitindo valorizar adequadamente o trabalho das equipes de atenção primária.

Em todos os centros que visitei, constatei a responsabilidade, o profissionalismo e a empolgação de todas as pessoas das equipes que tive o prazer de conhecer.

O trabalho docente que está sendo feito pelos preceptores e pela coordenação da unidade docente é crucial para ter uma rede de profissionais médicos qualificados e para apoiar o desenvolvimento de uma atenção primária de qualidade.

RBMFC: No Brasil, alguns anos atrás, um debate frequente era se os programas de residência deveriam estar vinculados às universidades. Na Espanha, os programas de residência estão vinculados às universidades?

Pilar Astier: Na Espanha, os programas de residência médica não dependem das universidades. O sistema de formação médica especializada, também conhecido como MIR (médico interno residente), é coordenado pelo Ministério da Saúde, que anualmente lança o edital para um exame único de seleçáo para toda a Espanha e realiza a oferta de vagas nos diferentes hospitais do sistema público de saúde para cada especialidade. Esse sistema começou em 1978.

Um conselho nacional de especialistas em ciências da saúde e um comitê específico de cada especialidade são encarregados de elaborar o programa de formação e de certificar as unidades docentes hospitalares e de atenção primária onde se desenvolve a formação. Essas unidades são avaliadas periodicamente para garantir o correto cumprimento do programa.

RBMFC: É obrigatório ter o título de especialista para poder trabalhar no sistema público na Espanha?

Pilar Astier: O programa MIR é obrigatório atualmente para poder exercer a medicina na Espanha e em qualquer outro país da União Europeia (Portaria 2005/36/CE).

RBMFC: Como está a situação da pesquisa na atenção primária? Como é a relação da universidade com o sistema de saúde?

Pilar Astier: A situação da pesquisa na atenção primária está melhorando, graças à criação dos institutos de pesquisa dos serviços regionais de saúde. Esses institutos públicos facilitam os trabalhos burocráticos dos pesquisadores com as entidades de financiamento como, por exemplo, em relação às bolsas oferecidas pelas comunidades autônomas, pelo Ministério da Saúde, pelo Conselho da Europa e pela indústria farmacêutica. A tomada de decisáo sobre a concessão de bolsas de pesquisa envolve um processo longo e complexo de documentação, como também o posterior gerenciamento dos recursos concedidos, e esses institutos de pesquisa regionais têm facilitado o trabalho dos pesquisadores.

De fato, já foram iniciados ensaios clínicos sobre medicamentos na atenção primária, e estamos conseguindo projetos de pesquisa colaborativa com outros países europeus.

Também as sociedades científicas de médicos de atenção primária estão apoiando o desenvolvimento de linhas de pesquisa em doenças crônicas, como hipertensão, diabetes, dor crônica, entre outras.

Alguns profissionais médicos estabeleceram vínculos formais com as faculdades de Medicina, tornando-se professores associados. Esses professores associados ministram as aulas teóricas nas faculdades e as práticas em seus próprios consultórios, geralmente situados nos serviços regionais de saúde. Na maior parte das faculdades náo existe departamento de medicina de família e comunidade. Os médicos de família e comunidade que colaboram como professores associados integram-se em outros departamentos. É por isso que os médicos de família e comunidade não costumam desenvolver projetos de pesquisa em atenção primária vinculados às faculdades.

Existem 21 faculdades de medicina públicas e 7 privadas. 
RBMFC: No Brasil existe uma importante falta de médicos de família e comunidade. Como é a situação na Espanha? Existem médicos de família e comunidade suficientes para dar conta de toda a população?

Pilar Astier: Atualmente a Espanha tem um superávit de médicos de família e comunidade. Isso faz com que, em muitas ocasióes, a oferta de vagas melhor pagas e com boas condiçôes de trabalho seja escassa, porque existem muitos profissionais que querem essas vagas.

De fato, muitos médicos de família e comunidade estão migrando para a Inglaterra, França, Suécia, Noruega e Alemanha em busca de emprego. Nesses países eles são muito benquistos em função do seu alto nível de qualificação.

\section{RBMFC: Qual é a cobertura da atenção primária na Espanha?}

Pilar Astier: $\mathrm{Na}$ Espanha praticamente 99\% da população tem cobertura pelo Sistema

"Na Espanha praticamente 99\% da população tem cobertura pelo Sistema Nacional de Saúde".
Nacional de Saúde.

Os serviços públicos oferecidos pelas equipes de atenção primária no Sistema Nacional de Saúde espanhol incluem atividades preventivas, diagnósticas, terapêuticas e de reabilitação, bem como de promoção da saúde. A carteira básica de serviços está regulamentada pela Lei 16/2003, que trata sobre a integração e a qualidade do Sistema Nacional de Saúde, e pela Portaria 1030/2006, que estabelece o elenco comum da carteira de serviços e os procedimentos para sua atualização.

A "Reforma Sanitária sobre Medidas Urgentes para Garantir a Sustentabilidade do Sistema Nacional de Saúde e Melhorar a Qualidade e a Segurança de seus Serviços" (Real Decreto 16/2012, de 20 abril de 2012) modificou a carteira de serviços. Esse decreto criou uma carteira básica de serviços à qual cada comunidade autônoma poderá acrescentar os serviços que achar pertinentes. Ele restringiu a cobertura de serviços aos cidadãos que tenham contribuído com a Previdência Social e aos seus familiares beneficiários. Os que não contribuíram devem assinar um seguro público mediante pagamento mensal. A atenção às situaçôes de urgência, tanto na atenção primária quanto nos hospitais, é garantida para todas as pessoas.

Quando são prescritos fármacos pelo médico de família e comunidade, o paciente tem uma participação no custeio, que é proporcional ao seu nível de renda mensal. As pessoas com rendas muito baixas ficam isentas desse co-pagamento.

Texto editado por Michael Schmidt Duncan a partir de entrevista concedida por email por Pilar Astier, com perguntas elaboradas por Lourdes Luzon Oliver e Inaiara Bragante, em parceria entre o Programa de Residência de Medicina de Família e Comunidade da Secretaria Municipal de Saúde do Rio de Janeiro, a Rede de Pesquisa em Atenção Primária da ABRASCO e a Revista Brasileira de Medicina de Família e Comunidade.

Tradução: Jacob Pierce 